\title{
Appetite and nutrition in relation to human immunodeficiency virus (HIV) infection and acquired immunodeficiency virus syndrome (AIDS)
}

\author{
BY CAROLYN SUMMERBELL \\ Rank Department of Human Nutrition, St Bartholomew's Hospital Medical College, \\ Charterhouse Square, London ECIM $6 B Q$

\begin{abstract}
WHY ARE WE INTERESTED IN WHAT PEOPLE WITH HUMAN IMMUNODEFICIENCY VIRUS (HIV) INFECTION AND ACQUIRED IMMUNODEFICIENCY VIRUS SYNDROME (AIDS) EAT?
\end{abstract}

Interest in what people with HIV infection and AIDS eat focuses on the possibility that by consuming a certain type of diet, or by ingesting a certain amount of a particular nutrient, the HIV-positive individual can live longer. This is not an unreasonable suggestion since there is a popular belief that evidence exists for an 'anti-heart disease diet', so why not an 'anti-AIDS diet'?

Of particular interest is the possibility that the HIV-positive individuals, by altering their diet, can extend the period of time when they are otherwise well (the asymptomatic phase). This concept has been seized upon by those who promote alternative types of diets and dietary supplements, and has resulted in a wealth of information directed at this vulnerable group (Pike, 1988). This information promises the newly diagnosed individual that by taking megadoses of vitamin $\mathrm{C}$, or large quantities of acidophilus yoghurt, Chinese herbs, or by 'going macrobiotic', they can keep well for longer (Dwyer et al. 1988). Although many patients believe that such changes may improve their chances of survival (Bandy et al. 1993), particularly the use of vitamin and mineral supplements (Martin et al. 1991), the scientific evidence on which they are based is mostly deplorable. Furthermore, they may be harmful when taken in excess or in combination with other therapies, including prescribed drugs (Gowen et al. 1993).

Many patients also believe that they should be changing their diet along the lines of the healthy eating guidelines recommended for the general public (Summerbell et al. 1993a). However, this 'healthy diet' is aimed at reducing avoidable mortality from coronary heart disease and stroke, and since this relatively young patient group is more likely to die of AIDS than any other cause of death, this 'healthy diet' may be less appropriate for these individuals. There is also some evidence that immune function can be improved by altering the lipid or amino acid composition of the diet (Grimble, 1989), and the use of supplements which contain specific lipids or amino acids, particularly arginine, appears increasingly popular in this client group (Bandy et al. 1993).

There is also interest in the possibility that diet may help in controlling some of the non-specific symptoms which develop during the symptomatic phase of HIV disease; particularly popular is the anti-candida diet for the treatment of oral candida. However, once the patient acquires one of a number of specific opportunistic infections or cancers which gives that patient a diagnosis of AIDS, the emphasis which the patient places on diet as a means of improving or maintaining health appears to shift towards the role it may play in the maintenance of body weight (Broderick \& Nesset, 1989). Severe weight loss is a common problem during the latter stages of HIV disease (Ysseldyke, 1991) and, 
as will be shown below, the AIDS patient is well justified in seeing their weight as a marker of their health.

In summary, regardless of the wealth of interest in the possibility that changes in diet, such as those cited previously, may prolong survival and improve symptomatic control, it is difficult to be confident about recommending such changes since they remain unproven. However, the health professional should keep an open mind regarding the patients' perception of the potential health benefits of alternative therapies for two reasons. First, their use does appear to confer some psychological benefit to the patient by empowering them to take control of their own health (Peck \& Johnson, 1990), and second, we do not know that they are not beneficial. The lack of scientific evidence either way places the health professional who is asked about the 'anti-AIDS diet' in a difficult position. However, it may be possible to make certain recommendations about diet in terms of energy intake on the basis that there is some evidence that body weight is associated with survival and so, in theory, there may be an ideal body weight for which the patient can aim.

\section{WHAT IS THE RELATIONSHIP BETWEEN BODY WEIGHT AND SURVIVAL?}

The obvious method of finding out the answer to this question would be systematically to review the medical records of HIV-positive individuals who have died and chart their weight in relation to height with survival. In patients with AIDS it is clear that those who are heavier live longer than those who are thinner (Kotler et al. 1989a), and those who have lost a greater proportion of their body weight die earlier than those who have lost less (Chlebowski et al. 1989). Although interesting, this information does not tell us what the ideal body weight is for patients with AIDS since there does not appear to be a body weight above which survival levels off. This is probably due to the fact that even those patients who were heaviest or who had lost the least amount of weight were not overweight and had already lost significant amounts of weight.

Those of us who have attempted to look at the relationship between body weight during the asymptomatic and symptomatic phases of the disease in relation to survival have failed because at the time when these patients were otherwise well (up to 10 years ago) weights were not routinely recorded. The usefulness of routinely recording height and weight in all patients is highlighted in a recent editorial by Grunfeld \& Feingold (1993), and this practice now appears to be standard in most clinics in Europe and America. We are left with two possible methods by which we could answer our original question. First, we could ask a group of AIDS patients what they weighed at various times in the past and, after they have died, correlate this with survival. This method has the advantage of producing a complete data set in a couple of years time, but the disadvantage of relying on the patient remembering accurately what they weighed in the past (Rowland, 1990). Second, we could monitor a cohort of newly diagnosed patients through until death. This has the disadvantage of potentially taking 10 years before producing a complete set of data, but has the advantage of being accurate. Analyses using both methods are currently under way.

Another approach would be to look at existing mortality data for specific diseases which have a wasting component of similar pathogenesis to that observed in HIV infection, such as lung cancer and stomach cancer. Ideal body weight (regardless of age and sex) is higher for these types of cancer compared with those diseases which are exacerbated by obesity, such as cerebrovascular disease (Whaaler, 1980). One may 
suggest, therefore, that the ideal body weight for the newly diagnosed HIV-positive individual is above that for total mortality.

In conclusion, the evidence suggests that patients with HIV infection may prolong their survival by aiming for a body mass index (BMI) in the range of 25-30. Indeed, epidemiological evidence shows that, between 1984 and 1990 , both seronegative and seropositive gay men gained weight at a greater rate as compared with heterosexual men $(3.7 \mathrm{~kg}$ more than expected), reflecting an intentional effort to increase body weight (Hoover et al. 1992). This is consistent with a changing perception in the gay community of the association between low body weight and HIV disease. However, some patients appear to take this to extremes and deliberately overeat, gain weight and become obese in an attempt to postpone the onset of AIDS (Smith \& Birmingham, 1990; Ramsay et al. 1992). Although this behaviour has been classified as an eating disorder, these patients may well be improving their health by being obese.

\section{WHAT IS THE RELATIONSHIP BETWEEN BODY COMPOSITION AND SURVIVAL?}

In terms of body composition, work by Kotler et al. $(1985,1989 b)$ suggests that for AIDS patients, survival may be more closely related to lean body mass (LBM) than body weight. Again, these findings do not tell us what the ideal body composition is for AIDS patients, nor what it may be in the earlier stages of the disease. However, these findings do suggest that LBM may be protective against the onset of AIDS, and HIV-positive individuals often choose to include physical exercise programmes as part of their self-care strategies in an attempt to promote muscle mass (Lovejoy et al. 1988). Preliminary studies suggest that physical activity programmes may be useful in promoting muscle mass in both asymptomatic patients (Schlenzig et al. 1992) and also in AIDS patients who have lost significant amounts of weight (Spence et al. 1990), although data are not yet available to assess whether the development of LBM during the early stages of HIV infection improves survival.

\section{WHAT DIETARY ADVICE SHOULD WE GIVE?}

Dietary advice for the patient with HIV infection should focus on energy intake based on the body weight of that individual. If one assumes that the ideal body weight for such an individual is in the range of BMI 25-30, then the patient's diet should be manipulated to attain this goal. State Registered Dietitians are best placed to carry out such a task since they have unique skills in this area. One can also recommend some form of physical activity, so long as this is not too strenuous.

\section{THIS ADVICE SEEMS SIMPLE, SO WHY ALL THE FUSS?}

This advice would appear simple but, for a number of reasons listed below, current medical opinion does not believe that a decrease in appetite and energy intake is a major factor in the pathogenesis of weight loss associated with HIV disease, or value the role of diet in maintaining or attaining ideal body weight following weight loss (Raiten, 1990). Instead, this weight loss is seen as an inevitable consequence of the disease which is caused either by the HIV virus itself, resulting in an increase in the rate of muscle wasting and metabolic rate (via an increase in cytokine activity) and also malabsorption, or by 
the opportunistic infections and cancers specific to AIDS. The resultant weight loss which is thought to be caused by the virus itself has been termed 'unexplained weight loss', and has even been classified as a syndrome: the 'wasting syndrome'. The reasons why current medical opinion supports the concept of this 'wasting syndrome' are listed as follows:

1. the pattern of weight loss during the early stages of HIV disease is progressive;

(wrong);

2. efficacy of dietetic intervention to reverse severe weight loss in AIDS patients is poor; (correct, but ....);

3. HIV patients at all stages of the disease appear to consume similar amounts of energy compared both with each other and seronegative controls; (correct, but ...); 4. HIV patients at all stages of the disease appear to have depleted stores of LBM and a raised resting metabolic rate, implying sustained and unremitting cytokine activity;

(debatable);

5. most HIV-positive patients appear to have some degree of malabsorption;

(correct, but ....).

I would like to discuss the evidence for each of these statements in turn, and ultimately show that there is a real possibility that a significant proportion of 'unexplained weight loss' associated with HIV disease may be caused by a decrease in appetite and energy intake. The identification of the cause of weight loss is important because if it is associated with a decrease in energy intake, rather than an increase in muscle wasting and metabolic rate (via an increase in cytokine activity), and also malabsorption, then it is much easier to reverse by dietetic intervention (Hellerstein et al. 1992).

\section{The pattern of weight loss}

Although the greatest losses in weight occur during the end stages of HIV disease and are associated with opportunistic infections and cancers (Macallan et al. 1993a), crosssectional data suggest that significant amounts of weight are also lost during the asymptomatic and symptomatic stages of HIV disease (McCorkindale et al. 1990). Current medical opinion supports the view that this 'unexplained weight loss' during the earlier stages of disease is caused by the HIV virus itself. If this were true, then weight would be lost steadily and progressively.

However, subsequent analysis of the data collected as part of a study on the causes of weight loss associated with HIV infection (Summerbell et al. 1993b) shows that the pattern of weight loss is not progressive, but episodic (Table 1). Over the same 1-year period, approximately half the patients had remained weight stable, one-quarter had lost weight and one-quarter had gained weight. As expected, of those who had lost weight, weight loss was more common and more severe in AIDS patients. But, patients at all stages of disease did go through periods of weight gain, even AIDS patients. These findings show that 'unexplained weight loss' is neither progressive nor inevitable, and, therefore, unlikely to be caused by the HIV virus itself.

\section{Dietetic efficacy}

Most patients referred to the State Registered Dietitian because of weight loss do not, after consultation, begin to gain weight. However, most patients referred are not only 
Table 1. Degree of weight gain and weight loss dependent on stage of human immunodeficiency virus (HIV) disease

(Mean values and standard deviations)

\begin{tabular}{|c|c|c|c|}
\hline & Asymptomatic & Symptomatic & AIDS \\
\hline \multicolumn{4}{|c|}{ Wt gainers ( $22 \%$ total sample) } \\
\hline$n$ & 38 & 40 & 14 \\
\hline$\%$ total wt gainers & 41 & 43 & 15 \\
\hline \multicolumn{4}{|l|}{ Wt gain $(\mathrm{kg})$} \\
\hline Mean & $5 \cdot 0$ & $5 \cdot 0$ & $5 \cdot 3$ \\
\hline SD & $2 \cdot 6$ & $1 \cdot 9$ & $2 \cdot 7$ \\
\hline \multicolumn{4}{|c|}{ Wt losers ( $29 \%$ total sample) } \\
\hline$n$ & 21 & 41 & 59 \\
\hline$\%$ total wt losers & 17 & 34 & 49 \\
\hline \multicolumn{4}{|l|}{ Wt loss $(\mathrm{kg})$} \\
\hline Mean & $5 \cdot 2$ & $5 \cdot 6$ & $8 \cdot 2$ \\
\hline $\mathrm{SD}$ & $2 \cdot 5$ & $2 \cdot 5$ & $3 \cdot 6$ \\
\hline
\end{tabular}

AIDS, acquired immunodeficiency virus syndrome.

AIDS patients but are losing weight at the time of referral and this weight loss is usually associated with at least one opportunistic infection (Summerbell et al. 1993a). In such a patient it is likely that cytokine activity is raised, causing an increase in muscle wasting, metabolic rate and anorexia. Attempts to reverse this weight loss by increasing energy intake via dietary manipulation alone are unlikely to succeed (Kotler et al. 1991). Only when such patients are fed aggressively using enteral or total parenteral nutrition can body weight be replenished, although this is mainly fat, not LBM (Kotler et al. 1990a; Hellerstein et al. 1992). The most successful way of reversing body weight and LBM loss associated with opportunistic infections is by successfully treating the underlying infection (Kotler et al. 1989a; Kotler, 1991).

However, dietetic intervention can be efficacious in terms of replenishing body weight and LBM when targeted towards malnourished patients who do not have an acute systemic infection (Kotler et al. 1990a; Hellerstein et al. 1992). Appetite stimulants (Summerbell et al. 1992), exercise programmes (Spence et al. 1990), and even growth hormone (Grunfeld et al. 1992a) can enhance the rate of weight gain when used in conjunction with dietetic intervention. Of practical importance, these findings suggest that dietetic efficacy may be improved if nutritional intervention was focused more in outpatients rather than on the hospital ward.

\section{Energy intake}

Cross-sectional studies which have assessed food intake during HIV infection have found that, in clinically- and weight-stable patients, energy intake does not differ with the stage of HIV disease, body weight or compared with seronegative controls (Dworkin et al. 1990; Hommes et al. 1990; Kotler et al. 1990b; Foskett et al. 1991; Sharkey et al. 1992). However, the dietary records of these patients do not tell us about energy intake during periods of weight loss and, as highlighted by Dworkin et al. (1990), food intake may have 
been reduced during periods of weight loss before the time of study. Indeed, weightlosing patients with AIDS suffer a dramatic reduction in appetite and energy intake (Grunfeld et al. 1992b) and the degree of weight loss is closely correlated with the reduction in energy intake (Macallan et al. 1993b). Whether energy intake is reduced during periods of weight loss not associated with opportunistic infections remains unknown. However, it is possible that energy intake, like body weight, fluctuates over the course of the disease, and that these fluctuations mirror one another.

In summary, it would appear that periods of weight loss are probably associated with periods of reduced energy intake. These findings also suggest that short-term decreases in food intake may not be compensated for between periods of weight loss. This highlights the point made earlier that dietetic intervention should be targeted towards those individuals attending outpatients rather than those admitted to hospital.

To quantify the role which energy intake plays in the pathogenesis of weight loss a prospective study needs to be conducted. The methodology of such a study should involve the use of a simple technique to assess energy intake since patients who are losing weight are more likely to be feeling unwell and, therefore, less likely to complete a dietary record. For example, a simple diet diary or food-frequency questionnaire may be more appropriate than a weighed dietary intake. Also, because of the potential for greater variation in energy intake between days due to sickness, food intake should be assessed over a longer period of time than that recommended for healthy individuals (Nelson et al. 1989).

\section{Muscle wasting, hypermetabolism and cytokine activity}

Muscle in relation to fat is wasted to a greater degree in AIDS patients as compared with the body composition of individuals who are simply starved (Kotler et al. 1989b). Indeed, the changes in body composition are similar to those observed in other infectious conditions, sepsis and trauma. These changes in body composition appear to occur early in the course of HIV disease (Ott et al. 1993), suggesting an alteration in host metabolism caused by the HIV virus itself.

Other evidence for an alteration in host metabolism caused by the virus itself comes from the observation that resting metabolic rate (REE) is raised by about $11 \%$ in clinically stable HIV-positive patients compared with controls, regardless of the stage of HIV disease or the degree of malnutrition (Hommes et al. 1990, 1991; Melchior et al. 1991, 1993; Grunfeld et al. 1992b). This evidence is in conflict with the results of one study which found that REE was reduced in six clinically-stable malnourished AIDS patients (Kotler et al. 1990b). However, on balance it seems likely that HIV patients do have a raised REE, which increases by a further $30 \%$ during periods of weight loss associated with opportunistic infections (Grunfeld et al. 1992b; Melchior et al. 1993).

Regardless of the cause of muscle wasting and raised REE in the early stages of HIV disease, the role they play in the pathogenesis of weight loss remains unclear. If muscle wasting and raised REE are significant causes of weight loss in the early stages of HIV infection then weight would be lost progressively. However, as shown previously, HIV-positive patients do not lose weight progressively, but during distinct episodes. Therefore, any losses attributable to muscle wasting and raised REE must be defended during periods of weight stability and weight gain by either an increase in energy intake and/or a reduction in total energy expenditure (TEE). 
The role of reduced energy intake in the pathogenesis of weight loss may be significant, as described previously. The possibility that HIV patients early in the course of disease can reduce TEE during periods of weight loss is unknown, but weight-losing AIDS patients do conserve energy by reducing TEE (Macallan et al. 1993b). Indeed, a reduction in TEE under such circumstances is a normal metabolic adaptation to starvation, and the component of TEE which is specifically reduced is voluntary physical activity (Shetty, 1993). This adaptation produces the classical picture of the weak and fatigued starving individual. Indeed, a 'lack of energy' is frequently reported by HIV-positive individuals (Peck \& Johnson, 1990).

An increase in cytokine activity induced by the HIV virus itself has been proposed as the mechanism underlying the muscle wasting and hypermetabolism observed in patients with HIV infection. However, the mediator for this mechanism has not been identified. Levels of thyroid hormones, catecholamines and cortisol all appear within normal ranges, and conflicting reports on concentrations of tumour necrosis factor, interleukin-1 and interleukin- 6 make it difficult to speculate on the potential role of these cytokines either in the wasting syndrome or in increased REE (Melchior et al. 1993).

\section{Malabsorption}

Unexplained diarrhoea is occasionally reported by asymptomatic HIV-positive patients and it has been suggested that an enteropathy is induced directly by the HIV virus (Keusch \& Farthing, 1990). The demonstration of HIV-1 in the small and large intestinal mucosa of patients with AIDS strengthens the evidence that HIV may have a primary effect on intestinal function (Nelson et al. 1988). Furthermore, partial villous atrophy in the absence of detectable enteropathogens has been detected in asymptomatic subjects and is correlated quantitatively with the degree of fat malabsorption and the subjective presence of diarrhoea (Miller et al. 1988).

It should also be noted that diarrhoea associated with a specific pathogen is a common finding in asymptomatic gay men, regardless of their HIV status (Kotler et al. 1984). This is consistent with reports of a relatively high incidence of gastrointestinal problems in homosexual men, called the gay bowel syndrome (Urrutia \& Fedorak, 1988).

However, regardless of the cause of diarrhoea and malabsorption in the early stages of HIV disease, the role they play in the pathogenesis of weight loss remains unknown. If the diarrhoea and malabsorption induced by HIV enteropathy are significant causes of weight loss in the early stages of HIV infection then weight would be lost progressively. However, as shown earlier, HIV-positive patients do not lose weight progressively, but during distinct episodes. Therefore, any losses attributable to HIV enteropathy must be defended during periods of weight stability and weight gain by either an increase in energy intake and/or a reduction in TEE.

In summary, I suggest that there is a real possibility that a decrease in appetite and energy intake may be responsible for the majority of 'unexplained weight loss' associated with HIV infertion. And, to go back to my original point, this is important since weight loss associated with a decrease in appetite and energy intake, rather than an increase in muscle wasting and metabolic rate (via an increase in cytokine activity), and also malabsorption, is much easier to reverse by dietetic intervention.

Obviously, to understand fully the causes of weight loss associated with HIV disease and the mechanisms underlying them a prospective study needs to be conducted 


\section{WHAT FACTORS COULD CAUSE A DECREASE IN APPETITE AND ENERGY} INTAKE?

As mentioned previously, anorexia is one of the inevitable consequences of cytokine activity which is increased in response to opportunistic infections such as those seen in AIDS, possibly due to the release of interleukin-1 (McCarthy et al. 1985). However, there are a number of other factors which can depress appetite and/or reduce energy intake during all stages of HIV disease. A comprehensive discussion of these factors is given elsewhere (Thomas, 1994), and the list which follows should be viewed as a summary.

\section{Anxiety and depression}

A variety of psychological factors can occur during HIV infection and interfere with food intake; anxiety and depression are often cited by patients as the cause of their reduced appetite. (Why this should have the opposite effect in many obese patients is unclear!) Weak and fatigued patients may find it too difficult to shop for and prepare meals. In addition, economic factors may also contribute to a decreased food intake. Many patients, who may be too ill to work, cannot obtain medical insurances, find their insurance coverage is exhausted, or cannot afford the increased cost of insurance once they are diagnosed with HIV or AIDS.

\section{Mechanical problems}

Oral and/or oesophageal conditions or lesions are commonly associated with HIV infection and can make eating difficult, unpleasant, or painful, and result in voluntary food restriction. Oral and oesophageal candida is probably the most common cause of dysphagia seen in HIV disease. Occasionally, difficulty in eating can occur as a side effect of some of the prescribed drugs used in the management of this disease. For example, the use of DDI (Dideoxyinosine), an antretroviral currently on trial in many centres in the UK, can cause a dry, sore mouth.

\section{Nausea and vomiting}

Nausea and vomiting, which can also cause food avoidance, may result from infectious complications, obstructions caused by tumours, or drug therapy. Septrin (cotrimoxazole), which is commonly used as a prophylaxis against pneumocystis carinii pneumonia (PCP), frequently causes nausea and patients taking this drug should be reviewed regularly for any changes in body weight. The use of recreational drugs appears more common in gay men, regardless of their HIV status, compared with the general public, and some of these drugs may depress appetite (Mohs et al. 1990). On the other hand, some patients report using marijuana as an appetite stimulant, and indeed a prescribable drug based on the famous weed (Dronabinol) is now available.

\section{Early satiety}

Early satiety may occur with massive hepatomegaly or splenomegaly caused by several complications of AIDS, or by infiltrative diseases of the stomach and small bowel. Food 
intake may also be reduced by dyspnea associated with respiratory complications and by adrenal insufficiency.

\section{Diarrhoea}

Diarrhoea may depress food intake, either because patients attempt to reduce faecal output by restricting food consumption or because of specific suppression of appetite as a response to the presence of unabsorbed nutrients in the lower intestine (Kotler et al. $1990 b$ ). A mediator for the latter process has not been identified, but its existence has been thought to contribute to weight loss seen in other conditions of intestinal injury and disease. Such a process could provide the explanation for the clinical observation that food intake is often greatest in the morning in patients with AIDS and malabsorption.

\section{Voluntary weight loss}

Some newly diagnosed patients may voluntarily reduce energy intake in an attempt to lose weight because they see themselves as fat and believe that to be slim would be healthier. This misconception comes from their belief that if being slim is a healthy body weight for the general public, then it should also be healthy for them. However, as has been shown previously, this probably is not the case. The health professional must try to deter the patient from losing weight without inducing fear or anxiety. Other patients may try alternative diets, such as the anti-candida diet or a macrobiotic diet, and lose weight because these types of restrictive diets have a low energy density. Indeed, this is one of the main arguments against the use of such diets. However, as stated earlier, the health professional should not appear negative about the use of such diets since they can offer psychological benefit, and a diet should be formulated which is both acceptable to the patient and provides an adequate energy intake.

\section{Hospitalization}

Finally, hospital food, even if you feel well, can depress your appetite.

The exact impact of these factors has received little attention, and there is a need for quantitative data to document these observations.

HOW SHOULD WE MANAGE WEIGHT LOSS ASSOCIATED WITH HIV INFECTION?

1. Each patient should have their height recorded and be weighed at every clinic visit.

2. The pattern of weight change in each patient should be regularly reviewed. This can be done by simply charting weight on a piece of graph paper and attaching it to the medical notes.

3. Any significant degrees of weight loss should be identified and the patient referred to the State Registered Dietitian who is best placed to assess the cause of the weight loss, and advise on changes in diet to increase energy intake if appropriate. 


\section{REFERENCES}

Bandy, C. E., Guyer, L. K., Perkin, J. E., Probart, C. K. \& Rodrick, G. E. (1993). Nutrition attitudes and practices on individuals who are infected with human immunodeficiency virus and who live in south Florida. Journal of the American Dietetic Association 93, 70-72.

Broderick, B. \& Nesset, J. (1989). Nutritional status parameters associated with psychological well being seen in AIDS/ARC clients at an outpatient clinic in San Francisco. In Proceedings of the Fifth International Conference on AIDS, Montreal, p. 469 Abstr.

Chlebowski, R. T., Grosvenor, M. B., Bernhard, N. H., Morales, L. S. \& Bulcavage, L. M. (1989). Nutritional status, gastrointestinal dysfunction, and survival in patients with AIDS. American Journal of Gastroenterology 84, 1288-1293.

Dworkin, B. M., Wormser, G. P., Axelrod, F., Pierre, N., Schwarz, E., Schwartz, E. \& Seaton, T. (1990). Dietary intake in patients with Acquired Immunodeficiency Syndrome (AIDS), patients with AIDSRelated Complex, and serologically positive human immunodeficiency virus patients: correlations with nutritional status. Journal of Parenteral and Enteral Nutrition 14, 605-609.

Dwyer, J. T., Bye, R. L., Holt, P. L. \& Lauze, S. R. (1988). Unproven nutrition therapies for AIDS: What is the evidence? Nutrition Today 23, 25-33.

Foskett, M., Kapembwa, M., Sedgwick, P. \& Griffin, G. E. (1991). Prospective study of food intake and nutritional status in HIV infection. Journal of Human Nutrition and Dietetics 4, 149-154.

Gowen, S. L., Erskine, D. \& McAskill, R. (1993). An assessment of the usage of non-prescribed medication by HIV positive patients. Hospital Pharmacy Practice 77-90.

Grimble, R. F. (1989). Cytokines: their relevance to nutrition. European Journal of Clinical Nutrition 43, $217-230$.

Grunfeld, C. \& Feingold, K. R. (1993). Body weight as essential data in the management of patients with human immunodeficiency virus infection and the acquired immunodeficiency syndrome. American Journal of Clinical Nutrition 58, 317-318.

Grunfeld, C., Mulligan, K., Hellerstein, M. \& Schambelan, M. (1992a). Growth hormone therapy promotes positive nitrogen balance and weight gain in AIDS. In Proceedings of the Eighth International Conference on AIDS, Amsterdam, PoB 3835 Abstr.

Grunfeld, C., Pang, M., Shimizu, L., Shigenada, J. K., Jensen, P. \& Feingold, K. R. (1992b). Resting energy expenditure, caloric intake and weight in human immunodeficiency virus infection and the acquired immunodeficiency syndrome. American Journal of Clinical Nutrition 55, 455-460.

Hellerstein, M., Hoh, R., Nesse, R., Pelfini, A., Faix, D., Clinton, R. \& Cope, F. (1992). Effects of nutritional supplements of different composition on nutritional status and gut histology in HIV wasting: metabolic abnormalities for prediction of nutrient unresponsivity. In Proceedings of the Eighth International Conference on AIDS, Amsterdam, PoB 3696 Abstr.

Hommes, M. J. T., Romijin, J. A., Endert, E. \& Saverwein, H. P. (1991). Resting energy expenditure and substrate oxidation in human immunodeficiency virus (HIV)-infected asymptomatic men: HIV affects host metabolism in the early asymptomatic stage. American Journal of Clinical Nutrition 54, 311-315.

Hommes, M. J. T., Romijin, J. A., Godfried, M. H., Eeftinck Schattenkerk, J. K. M., Buurman, W. A., Endert, E. \& Sauerwein, H. P. (1990). Increased resting energy expenditure in human immunodeficiency virus-infected men. Metabolism 39, 1186-1190.

Hoover, D. R., Graham, N. M. H., Palenick, J. G., Bacellar, H. \& Saah, A. J. (1992). Weight changes in HIV-1 seropositive and seronegative homosexual men. Nutrition Research 12, 297-305.

Keusch, G. T. \& Farthing, M. J. G. (1990). Nutritional aspects of AIDS. Annual Review of Nutrition 10. $475-501$.

Kotler, D. P. (1991). Cytomegalovirus colitis and wasting. Journal of the Acquired Immunodeficiency Virus Syndrome 4, Suppl. 1, S36-S41.

Kotler, D. P., Gaetz, H. P., Lange, M., Klein, E. B. \& Holtz, P. R. (1984). Enteropathy associated with the Acquired Immunodeficiency syndrome. Annals of Internal Medicine 101, 421-428.

Kotler, D. P., Tierney, A. R., Altilio, D., Wang, J. \& Pierson, R. N. (1989a). Body mass repletion during ganciclovir treatment in patients with acquired immunodeficiency syndrome. Archives of Internal Medicine 149, 901-905.

Kotler, D. P., Tierney, A. R., Brenner, S. K., Couture, S., Wang, J. \& Pierson, R. (1990b). Preservation of short-term energy balance in clinically stable patients with AIDS. American Journal of Clinical Nutrition $\mathbf{5 1}$ $7-13$. 
Kotler, D. P., Tierney, A. R., Culpepper-Morgan, J. A., Wang, J. \& Pierson, R. (1990a). Effect of home total parenteral nutrition on body composition in patients with acquired immunodeficiency syndrome. Journal of Parenteral and Enteral Nutrition 14, 454-458.

Kotler, D. P., Tierney, A. R., Ferraro, R., Cuff, P., Wang, J. \& Pierson, R. (1991). Enteral alimentation and repletion of body cell mass in malnourished patient with acquired immunodeficiency syndrome. American Journal of Clinical Nutrition 53, 149-154.

Kotler, D. P., Tierney, A. R., Wang, J. \& Pierson, R. E. (1989b). Magnitude of body-cell-mass depletion and the timing of death from wasting in AIDS. American Journal of Clinical Nutrition 50, 444-447.

Kotler, D. P., Wang, J. \& Pierson, R. (1985). Body composition studies in patients with the acquired immunodeficiency syndrome. American Journal of Clinical Nutrition 42, 1255-1265.

Lovejoy, N. C., Moran, T. A. \& Paul, S. (1988). Self-care behaviours and information needs of seropositive homosexualbisexual men. Journal of the Acquired Immunodeficiency Virus Syndrome 1, 155-161.

Macallan, D. C., Noble, C., Baldwin, C. \& Griffin, G. E. (1993a). Prospective analysis of patterns of weight change in stage IV HIV infection. American Journal of Clinical Nutrition 53, 417-424.

Macallan, D. C., Noble, C., Baldwin, C., Jebb, S. A., Prentice, A. M. \& Griffin, G. E. (1993b). Energy expenditure and weight loss in HIV infection. In Proceedings of the Ninth International Conference on AIDS, Berlin, PoB36-2374 Abstr.

McCarthy, D. O., Klugger, M. J. \& Vander, A. J. (1985). Suppression of food intake during infection: is interleukin-1 involved? American Journal of Clinical Nutrition 42, 1179-1182.

McCorkindale, C., Dybevik, K., Coulston, A. M. \& Sucher, K. P. (1990). Nutritional status of HIV-infected patients during the early disease stages. Journal of the American Dietetic Association 90, 1236-1241.

Martin, J. B., Easley-Shaw, T. \& Collins, C. (1991). Use of selected vitamin and mineral supplements among individuals infected with human immunodeficiency virus. Journal of the American Dietetic Association 91, $476-478$.

Melchior, J. C., Raguin, G., Boulier, A., Bouvet, E., Rigaud, D., Matheron, S., Casalino, E., Vilde, J.-L., Vachon, F., Coulaud, J.-P. \& Apfelbaum, M. (1993). Resting energy expenditure is increased in human immunodeficiency virus-infected patients: comparison between patients with and without secondary infections. American Journal of Clinical Nutrition 57, 614-619.

Melchior, J. C., Salmon, D., Rigaud, D., Leport, C., Bouvet, E., Detruchis, P., Vilde, J.-L., Vachon, F., Coulaud, J.-P. \& Apfelbaum, M. (1991). Resting energy expenditure is increased in stable, malnourished HIV-infected patients. American Journal of Clinical Nutrition 53, 437-441.

Miller, A. R. O., Griffin, G. E., Batman, P., Farquar, C., Forster, S. M., Pinching, A. J. \& Harris, J. R. W. (1988). Jejunal mucosal architecture and fat malabsorption in male homosexuals infected with Human Immunodeficiency Virus. Quarterly Journal of Medicine New Series 69, 1009-1019.

Mohs, M. E., Watson, R. R. \& Leonard-Green, T. (1990). Nutritional effects of marijuana. heroin, cocaine, and nicotine. Journal of the American Dietetics Association 90, 1261-1267.

Nelson. J. A., Wiley, C. A., Reynolds-Kohler, C., Reese, C. A., Margaretten, W. \& Levy, J. A. (1988). Human immunodeficiency virus detected in bowel epithelium from patients with gastrointestinal symptoms. Lancet i, 259-262.

Nelson, M., Black, A. E., Morris, J. A. \& Cole, T. J. (1989). Between- and within-subject variation in the nutrient intake from infancy to old age: estimating the number of days required to rank dietary intakes with desired precision. American Journal of Clinical Nutrition 50, 155-167.

Ott, M., Lembcke, B., Fischer, H., Jeger, R., Polat, H., Geier, H., Rech, M., Staszeswki, S., Helm, E. B. \& Caspary, W. F. (1993). Early changes of body composition in human immunodeficiency virus-infected patients: tetrapolar body impedance analysis indicated significant malnutrition. American Journal of Clinical Nutrition 57, 15-19.

Peck, K. \& Johnson, S. (1990). The role of nutrition in HIV infection. Journal of Hıman Nutrition and Dietetics 3, 145-157.

Pike, J. T. (1988). Alternative nutritional therapies - Where is the evidence? AIDS Patient Care 7, 31-33.

Raiten. D. J. (1990). Nutrition and HIV Infection. A Review and Evaluation of the Extant Knowledge of the Relationship Between Nutrition and HIV Infection. Bethesda; Life Sciences Research Office, Federation of American Societies for Experimental Biology.

Ramsay, N., Catalan, J. \& Gazzard, B. (1992). Eating disorders in men with HIV infection. British Journal of Psychiatry 160, 404-407.

Rowland, M. L. (1990). Self-reported weight and height. American Journal of Clinical Nutrition 52, $1125-1133$.

Schlenzig, C., Jaeger, H., Wehrenberg, M., Poppinger, J. \& Rieder, H. (1992). Physical exercise favourably influences the course of illness in patients with HIV and AIDS. In Proceedings of the Eighth International Conference on AIDS, Amsterdam, PoB 3401 Abstr. 
Sharkey, S. J., Sharkey, K. A., Sutherland, L. R., Church, D. L. \& GI/HrV Study Group (1992). Nutritional status and food intake in human immunodeficiency virus infection. Journal of the Acquired Immunodeficiency Virus Syndrome 5, 1091-1098.

Shetty, P. S. (1993). Chronic undernutrition and metabolic adaptation. Proceedings of the Nutrition Society $\mathbf{5 2}$, 267-284.

Smith, J. \& Birmingham, C. L. (1990). HIV seropositivity and deliberate weight gain. New England Journal of Medicine 322, 1089-1090.

Spence, D. W., Galantino, M. L., Mossberg, K. A. \& Zimmerman, S. O. (1990). Progressive resistance exercise: effect on muscle function and anthropometry of a select AIDS population. Archives of Physical Rehabilitation 71, 644-648.

Summerbell, C. D., Catalan, J. \& Gazzard, B. G. (1993a). A comparison of the nutritional beliefs of human immunodeficiency virus (HIV) seropositive and seronegative homosexual men. Journal of Human Nutrition and Dietetics 6, 23-37.

Summerbell, C. D., Perrett, J. P. \& Gazzard, B. G. (1993b). Causes of weight loss in human immunodeficiency virus infection. International Journal of STD \& AIDS 4, 234-236.

Summerbell, C. D., Youle, M., McDonald, V., Catalan, J. \& Gazzard, B. G. (1992). Megesterol acetate vs cyproheptadine in the treatment of weight loss associated with HIV infection. International Journal of STD \& AIDS 3, 278-280.

Thomas, B. (editor) (1994). Nutrition and HIV disease. In The Manual of Dietetic Practice, 2nd ed. Oxford: Blackwell Scientific Press.

Urrutia, F. M. \& Fedorak, R. N. (1988), Gay bowel syndrome. Medical Clinics of North America 17, 3300-3313.

Waahler, H. T. (1984). Height, weight and mortality. The Norwegian experience. Acta Medica Scandinavica, Suppl., 679.

Ysseldyke, L. L. (1991). Nutritional complications and incidence of malnutrition among AIDS patients. Joumal of the American Dietetic Association 91, 217-218. 